\title{
Characteristics of shoulder pain, muscle tone and isokinetic muscle function according to the scapular position of elite boxers
}

\author{
Ju-Hong Lee ${ }^{a \oplus \infty}$, Ho Kim ${ }^{b(1)}$, Won-Seob Shin ${ }^{a, b, c(1)}$ \\ ${ }^{a}$ Department of Physical Therapy, Graduate School of Health and Medicine, Daejeon University, Daejeon, Republic of Korea \\ ${ }^{b}$ Department of Physical Therapy, Graduate School, Daejeon University, Daejeon, Republic of Korea \\ ${ }^{c}$ Department of Physical Therapy, College of Health and Medical Science, Daejeon University, Daejeon, Republic of Korea
}

\begin{abstract}
Objective: The shoulders are a particularly an important body part for elite boxers. The purpose of this study was to investigate the characteristics of the upper trapezius (UT), infraspinatus (IS) muscle tone, pain, and isokinetic muscle function of shoulder movements such as external rotation, internal rotation, protraction, and retraction according to the scapular position of elite boxers of the Korean national team.

Design: Cross-sectional study.

Methods: Using the double square method, the scapular position was measured and divided into the forward scapular position group $(\mathrm{n}=8)$ with a measurement distance of $135 \mathrm{~mm}$ or more, and the normal scapular position group $(\mathrm{n}=10)$ with a measurement distance of less than $135 \mathrm{~mm}$. Through the numeric rating scale of the subject, the pain value displayed during movement was measured. The muscle tone of the subjects' UT and IS were measured. The isokinetic muscle function of ER, IR, protraction, and retraction were measured using isokinetic exercise equipment.

Results: The results of this study showed statistically significant differences when comparing muscle tone of the UT and IS, shoulder pain, isokinetic function of ER and IR, protraction, and retraction according to scapular position $(p<0.05)$.

Conclusions: The findings of this study were that shoulder muscle tone, pain, and isokinetic muscle function were affected according to the scapular position of elite boxers. In the future, this information may be a useful indicator when studying the effects of medium and long-term intervention in elite boxers who possess these characteristics.
\end{abstract}

Key Words: Athletes, Boxing, Muscles, Pain, Scapula

\section{Introduction}

A lot of people are participating in exercise to improve the quality of life in their daily lives. Among them, there are amateur athletes who enjoy sports as a hobby and elite athletes who exercise professionally. A common phenomenon in amateur athletes or elite athletes is that they are exposed to the risk of sports injuries [1,2]. Sports injuries are classified as chronic injuries caused by repeated loads, collisions with opponents or facilities during training or competition, and injuries caused by excessive loads on the musculoskeletal system. Sports injuries can be prevented beforehand, research on the mechanism of injuries, protective equipment or warm-up exercises can prevent acute injuries, and chronic injuries can be prevented by adjusting training methods or the exercise environment [3]. Boxing and hockey were the most common causes of acute sports injuries among male and female athletes in a study that analyzed sports injuries during the official training period for elite athletes, such as national athletes [4]. Boxing is a speculative event that re-

Received: 20 May, 2020 Revised: 3 June, 2020 Accepted: 8 June, 2020

Corresponding author: Won-Seob Shin (ORCID https://orcid.org/0000-0002-6515-7020)

Department of Physical Therapy, College of Health and Medical Science, 62 Daehak-ro, Dong-gu, Daejeon 34520, Republic of Korea Tel: 82-42-280-2294 Fax: 82-42-280-2295 E-mail: shinws@dju.kr

(c) This is an Open-Access article distributed under the terms of the Creative Commons Attribution Non-Commercial License (http://creativecommons.org/licenses/ by-nc/4.0) which permits unrestricted non-commercial use, distribution, and reproduction in any medium, provided the original work is properly cited.

Copyright ( 2020 Korean Academy of Physical Therapy Rehabilitation Science 
quires the person to move violently for 3 minutes and 3 rounds and competes with opponents, and is a high-strength game without sufficient recovery due to a 1-minute break between rounds [5]. Boxers continue to train their attack skills such as jabs, straights, hooks, and uppercuts, as well as evasive techniques such as ducking, weaving, and sway using shoulders along with various physical exercises such as speed, strength, muscle endurance, and cardiopulmonary endurance [6-8]. In a study record of physical injuries to sports players, the boxing event showed a high degree of injuries occurred with wrist bending due to differences in hitting angles, shoulder injuries due to long hooks, and back muscle tension due to training [9]. Athletes have reported that the likelihood of injuries is further increased by greater amount of training to improve performance and develop skills [10]. Shoulders are particularly important for boxers because of their movement characteristics, and when shoulder injuries appear, problems with training or performance can be fatal. In fact, it was suggested that the cause of shoulder injuries was more likely to be caused by wrong movement than hitting [11]. Recently, studies on the necessity of intervention are increasing through injury and physical characteristics of various athletes. There are studies that have investigated the characteristics of the shoulder joints of baseball players and swimmers that have mentioned the need for intervention, and suggested the importance of conditioning through the characteristics of golf players [12-14]. In previous studies, scapular position of elite athletes were measured for forward shoulder postures, and isokinetic muscle functions were compared to provide basic data for rehabilitation programs [15]. The forward shoulder posture appears as a shortening of the anterior shoulder muscles, such as the serratus anterior, upper trapezius (UT), and pectoralis muscles by pulling the front of the scapular, affecting body alignment and muscle weakness, causing pain in the head, neck, and shoulders. It is one of the unstable postures that negatively affect musculoskeletal function [16]. In Korea, studies related to the physical fitness of boxing athletes and studies related to exercise dynamics related to boxing movements have been reported $[17,18]$. However, there has been no research on the risk of injury due upper extremity function, muscle condition, and shoulder blade position for boxers, and this is very incomplete.

Therefore, the purpose of this study was to investigate the characteristics of pain, muscle tension, and isokinetic muscle function of the shoulder muscles according to the scapular position of elite boxers of the Korean national team.

\section{Methods}

\section{Participants}

This study recruited 18 elite male boxers who entered the National Olympic Team Jincheon Athletes' Village from December 2017 to October 2018. The selection criteria for the candidates were 1) those who were currently living as athletes and have entered the national Athletes' Village, and 2) those with no orthopedic history (surgery) within the past 3 months of the shoulder joint. The exclusion criteria were 1) those with neurological disorders on the shoulders and 2) those who could not participate due to severe shoulder pain during all evaluations or examinations of this study and exercise intervention. The subjects of this study agreed in writing to understand and participate in the purpose of this study and proceeded after being deliberated by the Institutional Review Board of Daejeon University (1040647-202004-HR014-01).

\section{Procedure}

Eight subjects in the forward scapula posture group and ten subjects in the normal scapula posture group were assigned after measuring the position of the shoulder blades of all subjects. The subject's subjective pain was measured after measuring the muscle tension of the upper and lower extensor muscles. Experiments were conducted using an isokinetic equipment to measure muscle strength of angular velocity of $60^{\circ}$ and angular velocity of $180^{\circ}$ for shoulder protraction, retraction, internal rotation (IR), and external rotation (ER).

\section{Outcome measures}

\section{Scapular position}

The double square method was used to measure the scapular position. The measuring position allowed the athlete to stand with his back against the wall in a relaxed position. The evaluator measured the distance between the front of the acromion process and the wall surface $[19,20]$. Double square (Model \#420EM; Johnson Level and Tool Manufacturing, Inc., Mequon, WI, USA) was used to measure the distance between the subject and the wall, and the right and left sides were measured twice alternately. A person with a scapular position of $135 \mathrm{~mm}$ or more was presented as an forward shoulder posture (Figure 1) [16].

\section{Muscle tone}

The Myoton Pro (Myoton AS, Tallin, Estonia) was used 


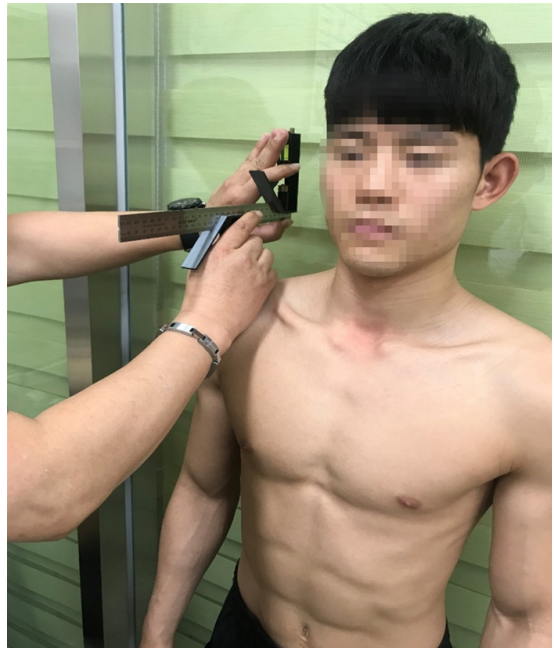

Figure 1. Double square methods.

to measure muscle tension in the shoulder muscle. Among the muscle tension of the shoulders, the examination was performed on the UT and IS muscles, which are correlated with the inward and backward rotations and the inner and outer rotations. In order to assess the muscle tone, UT was marked with a surgical marker pen in the middle part of the line connecting the spinous process of $\mathrm{C} 7$ and the end of the acromion, and the middle belly of the infraspinatus fossa for IS [21].

Subjects sat on a chair with a backrest to relax and maintain a comfortable posture. In repetitive measurement, one person performed the measurements in order to increase the internal reliability of the examiner. In the measurement environment, factors affecting the generation of resonant motion such as noise and vibration were limited and measured at an appropriate temperature $\left(22^{\circ} \mathrm{C}-24^{\circ} \mathrm{C}\right)$ and humidity $(45 \%$ $60 \%$ ). In order to produce accurate measurement variables, the subjects were instructed to avoid unnecessary tension to create resonant cavities in the tissue, and instructed to relax as much as possible during the measurement. Regardless of the measuring angle, the measuring probe (polycarbonate probe, $3 \mathrm{~mm}$ ) was always measured at a right angle (vertical) from the skin. In this study, all measurements were made using the Multiscan mode, and the average number of tap repetitions was measured three times, five times each, the mechanical impulse transmission time was set to 15 milliseconds, and the transmission interval was set to 0.8 seconds (Figure 2).

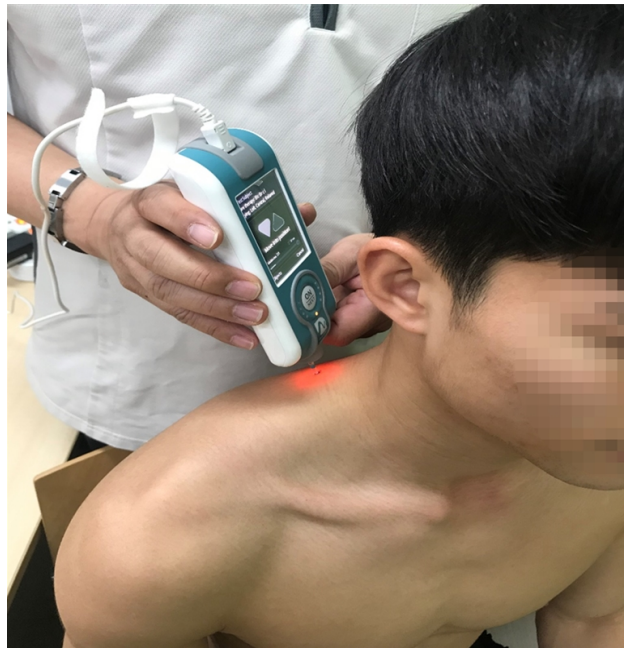

Figure 2. Myoton Pro (Myoton AS, Tallin, Estonia).

\section{Pain}

A numeric rating scale was used to evaluate shoulder pain during the subject's movement. After explaining that a 0 indicated that there was no pain at all, and a 10 indicated severe, unbearable pain, the subject was asked to quantify their current pain level. Subjective pain on the dominant shoulder of the subject was selected from 0 to 10 [22].

\section{Muscle performance}

Measurement of muscle function of the shoulder was performed using the Biodex System4 (Biodex Medical Systems, Shirley, NY, USA). For the measurement, the pre-training was conducted so that the maximum effort was made by the athletes during the measurement, and light warm-up exercises and stretches were performed for about 10 minutes. The measurement motions were measured for protraction and retraction, IR and ER. The shoulders and chest of the opposite side were fixed with a belt connected to the chair so that unnecessary movements other than the shoulders were not repeated. The dynamic strength evaluation of athletes was performed at a slow load speed of $60 \% \mathrm{sec}$ and a medium load speed of $180^{\circ} / \mathrm{sec}[23,24]$. In the order of protraction and retraction, after three exercises at angular velocity of $60 \% \mathrm{sec}$, the maximum force was measured five times on the right and left sides, and the angular velocity of $180^{\circ} / \mathrm{sec}$ on the right and left after three exercises. It was measured 20 times each alternately. In the order of measuring IR and ER, after 3 exercises at an angular velocity of $60 \% \mathrm{sec}$, it was measured right and left 5 times at maximum force, and after 


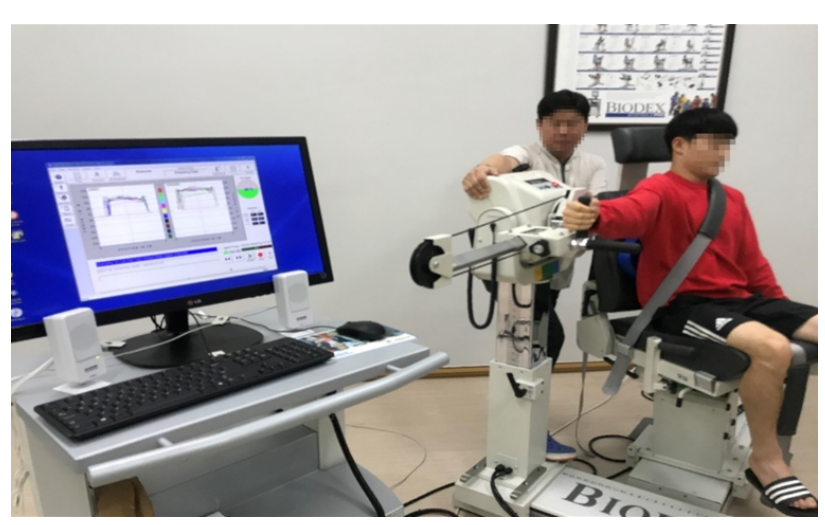

Figure 3. Biodex System4 (Biodex Medical Systems, Shirley, NY, USA).

3 exercises at $180^{\circ} / \mathrm{sec}$. The left was measured alternately 20 times (Figure 3) [25].

\section{Data and statistical analysis}

Data collected through this study were statistically processed using IBM SPSS Statistics for Windows, Version 25.0 (IBM Co., Armonk, NY, USA).

For the general characteristics of the subjects, the mean and standard deviation were presented using descriptive statistics, and an independent t-test and chi square test were conducted to test for homogeneity between groups. The Shapiro-Wilk test for normality test was performed and the independent t-test was used to compare the physical characteristics of elite boxers according to the scapular position. The statistical significance level was set to $\alpha=0.05$.

\section{Results}

\section{General characteristics of the study subjects}

There were eight subjects in the forward scapula posture groups and ten subjects in the normal scapula posture group. Table 1 shows the general characteristics such as age, height, weight, weight, and superior arm.

Comparison of pain and muscle tone between the two groups according to the scapular position. As a result of comparing the pain and muscle tone of each muscle according to the scapular position, statistically significant differences were shown in the muscle tension of bilatearl UT, dominant shouler pain and the IS muscle tone. Pain and low muscle tone were seen in the normal scapular position (NSP) group compared to the forward scapular position (FSP) group $(p<0.05)$ (Table 2).
Table 1. General characteristics of subjects

$(\mathrm{N}=18)$

\begin{tabular}{lccr}
\hline \multicolumn{1}{c}{ Variable } & $\begin{array}{c}\text { FSP group } \\
(\mathrm{n}=8)\end{array}$ & $\begin{array}{c}\text { NSP group } \\
(\mathrm{n}=10)\end{array}$ & $\chi^{2} / \mathrm{t}$ \\
\hline Age $(\mathrm{y})$ & $25.75(5.00)$ & $26.30(2.75)$ & -0.297 \\
Height $(\mathrm{cm})$ & $173.63(6.93)$ & $178.70(6.57)$ & -1.591 \\
Weight $(\mathrm{kg})$ & $68.38(19.14)$ & $72.30(12.18)$ & -0.530 \\
$\begin{array}{c}\text { Weight division } \\
\text { (light/heavy) }\end{array}$ & $5 / 3$ & $5 / 5$ & 0.281 \\
$\begin{array}{c}\text { Dominant arm } \\
\text { (left/right) }\end{array}$ & $3 / 5$ & $6 / 4$ & 0.900 \\
\hline
\end{tabular}

Values are presented as mean (SD) or number only.

FSP: forward scapular position, NSP: normal scapular position.

Table 2. Comparison on muscle tone and pain according to the scapular position $(\mathrm{N}=18)$

\begin{tabular}{lccc}
\hline \multicolumn{1}{c}{ Variable } & $\begin{array}{c}\text { FSP group } \\
(\mathrm{n}=8)\end{array}$ & $\begin{array}{c}\text { NSP group } \\
(\mathrm{n}=10)\end{array}$ & $\mathrm{t}$ \\
\hline NRS (points) & $5.25(0.71)$ & $1.90(0.57)$ & $11.167^{* *}$ \\
UT muscle tone (Hz) & & & \\
$\quad$ Right & $17.82(1.18)$ & $16.25(0.72)$ & $3.486^{* *}$ \\
$\quad$ Left & $17.38(0.98)$ & $16.09(1.27)$ & $2.356^{*}$ \\
IS muscle tone (Hz) & & & \\
$\quad$ Right & $14.68(1.08)$ & $13.05(0.93)$ & $3.439^{* *}$ \\
$\quad$ Left & $14.36(0.87)$ & $13.20(0.52)$ & $3.515^{* *}$ \\
\hline
\end{tabular}

Values are presented as mean (SD).

FSP: forward scapular position, NSP: normal scapular position, UT: upper trapezius, IS: infraspinatus, NRS: numeral rating scale.

${ }^{*} p<0.05,{ }^{* *} p<0.01$.

\section{Comparison of angular velocity $60 \% \mathrm{sec}$ muscle strength of two groups according to the scapular position}

As a result of comparing the angular velocity $60 \% \mathrm{sec}$ muscle strength of each movement according to the scapular position, there was a statistically significant difference in right protraction, rectraction, IR, ER, left protraction, retraction, IR, and ER. The NSP group showed greater muscle strength than the FSP group $(p<0.05)$ (Table 3$)$.

\section{Comparison of angular velocity $180^{\circ} / \mathrm{sec}$ muscle strength of two groups according to scapular position}

As a result of comparing the angular velocity $180^{\circ} / \mathrm{sec}$ muscle strength of each movement according to the position of the scapular, there was a statistically significant difference in the right protraction, retraction, IR, ER, left protraction, retraction, IR and ER. The NSP group showed greater muscle strength than the FSP group $(p<0.05)$ (Table 4). 
Table 3. Comparison of $60 \% \mathrm{sec}$ angular velocity peak torque of ER, IR, protraction, retraction according to scapular position

$(\mathrm{N}=18)$

\begin{tabular}{|c|c|c|c|}
\hline Variable & $\begin{array}{l}\text { FSP group } \\
\quad(n=8)\end{array}$ & $\begin{array}{l}\text { NSP group } \\
\quad(n=10)\end{array}$ & $\mathrm{t}$ \\
\hline \multicolumn{4}{|c|}{ Protraction strength $(\mathrm{Nm})$} \\
\hline Right & $287.69(52.97)$ & $387.38(37.44)$ & $-4.681 * *$ \\
\hline Left & $286.35(48.11)$ & $375.06(52.65)$ & $-3.688 * *$ \\
\hline \multicolumn{4}{|c|}{ Retraction strength (Nm) } \\
\hline Right & $350.63(105.51)$ & $431.02(80.61)$ & $-1.836^{*}$ \\
\hline Left & $298.64(81.48)$ & $416.68(67.12)$ & $-3.375^{* *}$ \\
\hline \multicolumn{4}{|c|}{ IR strength $(\mathrm{Nm})$} \\
\hline Right & $38.44(10.02)$ & $49.21(10.14)$ & $-2.251^{*}$ \\
\hline Left & $31.28(6.84)$ & $40.93(7.67)$ & $-2.819 * *$ \\
\hline \multicolumn{4}{|c|}{ ER strength $(\mathrm{Nm})$} \\
\hline Right & $24.50(4.69)$ & $33.45(6.57)$ & $-3.239 * *$ \\
\hline Left & $24.71(6.03)$ & $32.49(8.36)$ & $-2.291^{*}$ \\
\hline
\end{tabular}

Values are presented as mean (SD).

ER: external rotation, IR: internal rotation, FSP: forward scapular position, NSP: normal scapular position.

${ }^{*} p<0.05,{ }^{* *} p<0.001$

\section{Discussion}

The purpose of this study was to investigate changes in the characteristics of shoulder muscle pain, muscle tension, and isokinetic muscle function according to the scapular position of elite boxers. As a result of comparing the pain and muscle tension of each muscle according to the the scapular position, statistically significant differences appeared in right UT, IS, left UT, and inraspinatus pain. Pain and decreased muscle tone were seen in the FSP group compared to the NSP group $(p<0.05)$.

Due to the excessive use of the trapezius muscles, shoulder joint instability may occur due to relative muscle weakness or imbalance of the activation pattern between the muscles, and secondary impingement syndrome may appear [26]. It has been reported that if the shoulder range of motion is improved by reducing the tension of the UT muscles, the risk of injury to athletes can be reduced [21]. The IS muscle is the involved rotator cuff muscle of the shoulder joint. It has been reported to cause shoulder joint widening due to weakness or injury, limitation of ER, and instability of the shoulder joint, requiring continuous pain and range of motion evaluation [27-29]. Of these, if one of these muscles lose its function, in severe cases, pain and movement limitations appear, resulting in physiological deformation of the muscle, thereby reducing functions such as muscle strength and flexibility [30].
Table 4. Comparison of $180 \% \mathrm{sec}$ angular velocity peak torque of ER, IR, protraction, retraction according scapular position

$(\mathrm{N}=18)$

\begin{tabular}{|c|c|c|c|}
\hline Variable & $\begin{array}{l}\text { FSP group } \\
\quad(n=8)\end{array}$ & $\begin{array}{l}\text { NSP group } \\
\quad(n=10)\end{array}$ & $\mathrm{t}$ \\
\hline \multicolumn{4}{|c|}{ Protraction strength $(\mathrm{Nm})$} \\
\hline Right & $238.70(55.53)$ & $339.76(77.70)$ & $-3.093 * *$ \\
\hline Left & $218.94(57.92)$ & $307.75(68.13)$ & $-2.932 * *$ \\
\hline \multicolumn{4}{|c|}{ Retraction strength (Nm) } \\
\hline Right & $327.88(65.13)$ & $433.69(99.76)$ & $-2.709 * *$ \\
\hline Left & $292.03(90.91)$ & $405.84(79.83)$ & $-2.828 * *$ \\
\hline \multicolumn{4}{|c|}{ IR strength $(\mathrm{Nm})$} \\
\hline Right & $35.28(7.54)$ & $45.38(10.50)$ & $-2.286^{*}$ \\
\hline Left & $34.06(6.70)$ & $43.23(9.06)$ & $-2.383 *$ \\
\hline \multicolumn{4}{|c|}{ ER strength $(\mathrm{Nm})$} \\
\hline Right & $21.10(6.67)$ & $35.70(7.59)$ & $-4.274 * *$ \\
\hline Left & $18.36(4.47)$ & $25.94(5.53)$ & $-3.216 * *$ \\
\hline
\end{tabular}

Values are presented as mean (SD).

ER: external rotation, IR: internal rotation, FSP: forward scapular position, NSP: normal scapular position.

${ }^{*} p<0.05,{ }^{* *} p<0.001$.

As a result of comparing muscle strength of angular velocity $60^{\circ}$ and angular velocity $180^{\circ}$ for each movement according to the scapular position, statistically significant differences in right protraction, retraction, IR, ER and left protraction, retraction, IR, and ER were found, and the NSP group exhibited greater strength according to higher angular velocity compared to the FSP group $(p<0.05)$. Kim et al stated that ER and IR are important indicators for shoulder joint movement and require continuous evaluation [31]. Athletes who raised their arms frequently (overhead posture) reported structural deformation due to repeated training and many movements in abnormal scapular postures, and reported abnormal correlation with shoulder disease and abnormal shoulder postures or injuries. Abnormal scapular positions or injured shoulder joints were found to have decreased trapezius muscle activity [32,33]. In previous studies, abnormal scapular position was associated with concave glenohumeral joint movement [34].

Due to the nature of boxing, there is a structural imbalance in the shoulders depending on the position of the scapula. Previous studies have shown that the pre-punch phase of boxers have similarities to baseball pitching [35], and abnormal scapular positions and problems with shortening of the posterior and anterior joint capsule the shoulder joint in boxers may cause limited upper limb function and injury [11].

Having said that external and IR also affects muscle strength and endurance, shoulder injury not only leads to 
muscle strength loss but also affects performance in tennis players, and through the excessive use of the shoulder, such as in rowing players, it has been reported that myofascial pain and shoulder impingement syndrome are exhibited [36-38]. In addition, not only is it possible for field hockey athletes using isokinetic equipment during shoulder training to prevent injury of the serratus anterior, middle trapezius, and lower trapezius muscles, it has been reported that it prevents injury to the shoulder joint and improves performance [39].

Isokinetic exercise is widely used in training to improve muscle strength, agility, and endurance, as well as in studies involved with muscular contraction and speed, rehabilitation exercise, judgment of exercise effect, diagnosis and prescription of exercise condition. In relation to isokinetic exercise, the speed of the exercise load is the most important variable, and most of all, it is widely used to scientifically understand the local injury factors of athletes. Therefore, it is considered to be suitable as an evaluation tool for this study.

In this study, it was considered that it was appropriate to distribute the subjects to groups according to their scapular position, indicating the pathological condition of the shoulder joint through positive correlation with shoulder impingement syndrome [15].

There were a few limitations in this study. First, it is difficult to generalize the information obtained from the results due to the small number of subjects in the experimental group and the control group. Second, the athletes included in this study were composed of only male and so characteristics of female athletes could not analyzed. However, the results of this study are expected to be an important indicator in relation to shoulder injuries of boxers. Future studies will require mid- and long-term intervention studies of elite athletes with these characteristics, and further studies of areas with high risk of physical injury other than shoulder joint injuries are needed.

In conclusion, this study was was conducted with 18 elite athletes who qualified for the National Athlete's Village for Korean national boxing, and was conducted to investigate changes in the characteristics of shoulder pain, muscle tension, and isokinetic muscular function according to scapular position. As a result of comparing the pain and muscle tension of each muscle according to scapular position, statistically significant differences were found in the right, upper left back trapezius and IS muscles. In the NSP group compared to FSP group. Pain and decreased muscle tone were observed. As a result of comparing the isokinetic muscle function of $60^{\circ}$ and $180^{\circ}$ for each movement according to the scapular position, significant differences appeared in right and left protraction, retraction, IR, and ER. The NSP group exhibited greater muscle strength compared to the FSP group.

\section{Conflict of Interest}

The authors declared no potential conflicts of interest with respect to the authorship and/or publication of this article.

\section{References}

1. Uitenbroek DG. Sports, exercise, and other causes of injuries: results of a population survey. Res Q Exerc Sport 1996;67:380-5.

2. Lee JH. Sports injury and rehabilitation. J Coaching Dev 2008; $10: 31-40$

3. Lee KT, Song BY, Young KW, Kim NM, Kim CY, Park SR. Analysis of the injuries in professional soccer player. Korean $\mathrm{J}$ Sports Med 2000;18:176-80.

4. Kim EK, Kim TG. Analysis of sports injuries among Korean national players during official training. J Korean Data Inf Sci Soc 2014;25:555-65.

5. El-Ashker S, Nasr M. Effect of boxing exercises on physiological and biochemical responses of Egyptian elite boxers. J Phys Educ Sport 2012;12:111-6.

6. Whiting WC, Gregor RJ, Finerman GA. Kinematic analysis of human upper extremity movements in boxing. Am J Sports Med 1988;16:130-6.

7. Kim JJ, Ham WT, Lee YR. Biomechanics comparative analysis of the boxing hook punch according to skill level. Korean $\mathrm{J}$ Sports Sci 2013;22:1311-20.

8. Kim SJ, Woo BH. Biomechanical analysis of left and right hook type on trunk motion in boxing. Korean J Sports Sci 2013;22: 1519-29.

9. Kim TW, Choi KJ, Moon YJ, Song JH, Park SH, Kim EK, et al. Analysis of sports injury induced behavior in summer sports. Korean J Sport Sci 2015;26:690-701.

10. Lee KT, Kim JS, Choi BO. Analysis of seasonal injuries in professional football player. J Korean Orthop Soc Sports Med 2006; 5:135-40.

11. Lenetsky S, Brughelli M, Harris NK. Shoulder function and scapular position in boxers. Phys Ther Sport 2015;16:355-60.

12. Ahn NY, Kim HS, Kim KJ. Isokinetic muscle function and injury of shoulder joint in baseball player. J Coaching Dev 2013;15: 183-8.

13. Moon SJ, Kyeun SN, Kim B, Lee SJ, Eo SJ, Lee SS, et al. ROM characteristics of shoulder and hip joint in competitive swimmers. Korea J Sport 2017;15:743-54.

14. Hwang JH, Choi HS, Shin WS. Effects of real-time feedback training on weight shifting during golf swinging on golf performance in amateur golfers. Phys Ther Rehabilit Sci 2017;6:189-95. 
15. Kim HC, Kim YJ, Lee JH. The influences of forward shoulder posture on incidence of impingement syndrome and isokinetic muscular function in elite athletes. J Korea Soc Wellness 2017; 12:613-21.

16. Peterson DE, Blankenship KR, Robb JB, Walker MJ, Bryan JM, Stetts DM, et al. Investigation of the validity and reliability of four objective techniques for measuring forward shoulder posture. J Orthop Sports Phys Ther 1997;25:34-42.

17. Oh CH, Shin ES, Kim JP, Rho DS. The kinetics analysis on the one-two straight punch motion in boxing. Korean J Sports Sci 2012;21:1509-18.

18. Kim KJ, Song HS, Min SK. Body composition and specific physical fitness profiles of the Korean national amateur boxers. Exerc Sci 2016;25:33-42.

19. Moezy A, Sepehrifar S, Solaymani Dodaran M. The effects of scapular stabilization based exercise therapy on pain, posture, flexibility and shoulder mobility in patients with shoulder impingement syndrome: a controlled randomized clinical trial. Med J Islam Repub Iran 2014;28:87.

20. Laudner KG, Wenig M, Selkow NM, Williams J, Post E. Forward shoulder posture in collegiate swimmers: a comparative analysis of muscle-energy techniques. J Athl Train 2015;50:1133-9.

21. Kisilewicz A, Janusiak M, Szafraniec R, Smoter M, Ciszek B, Madeleine $\mathrm{P}$, et al. Changes in muscle stiffness of the trapezius muscle after application of ischemic compression into myofascial trigger points in professional basketball players. J Hum Kinet 2018;64:35-45.

22. Farrar JT, Troxel AB, Stott C, Duncombe P, Jensen MP. Validity, reliability, and clinical importance of change in a $0-10$ numeric rating scale measure of spasticity: a post hoc analysis of a randomized, double-blind, placebo-controlled trial. Clin Ther 2008;30:974-85.

23. Utter A, Gross F, Dasilva S, Kang J, Suminski R, Borsa P, et al. Development of a wrestling-specific performance test. J Strength Cond Res 1997;11:88-91.

24. Perrin DH. Isokinetic exercise and assessment. Champaign: Human Kinetics Publishers; 1993.

25. Roach KE, Budiman-Mak E, Songsiridej N, Lertratanakul Y. Development of a shoulder pain and disability index. Arthritis Care Res 1991;4:143-9.

26. Cools AM, Dewitte V, Lanszweert F, Notebaert D, Roets A, Soetens B, et al. Rehabilitation of scapular muscle balance: which ex- ercises to prescribe? Am J Sports Med 2007;35:1744-51.

27. Seitz AL, McClure PW, Finucane S, Boardman ND 3rd, Michener LA. Mechanisms of rotator cuff tendinopathy: intrinsic, extrinsic, or both? Clin Biomech (Bristol, Avon) 2011;26:1-12.

28. Park MC, Tibone JE, Lee TQ. History, physical examination, radiographic anatomy, and biomechanics and physiological function of the rotator cuff. Oper Tech Sports Med 2012;20:201-6.

29. Lee SH, Kim YH, Lee DG, Lee KB, Lee GC. Osteokinematic analysis during shoulder abduction using the $\mathrm{C}$-arm. Phys Ther Rehabilit Sci 2017;6:208-13

30. Ehrich D, Gebel R. Therapie und aufbautraining nach sportverletzungen. Munster: Philippka Sportverlag; 2000.

31. Kim BR, Yi DH, Yim JE. Effect of postural change on shoulder joint internal and external rotation range of motion in healthy adults in their 20s. Phys Ther Rehabilit Sci 2019;8:152-7.

32. Cools AM, Witvrouw EE, Declercq GA, Vanderstraeten GG, Cambier DC. Evaluation of isokinetic force production and associated muscle activity in the scapular rotators during a protraction-retraction movement in overhead athletes with impingement symptoms. Br J Sports Med 2004;38:64-8.

33. Cools AM, Witvrouw EE, Mahieu NN, Danneels LA. Isokinetic scapular muscle performance in overhead athletes with and without impingement symptoms. J Athl Train 2005;40:104-10.

34. Lewis JS, Wright C, Green A. Subacromial impingement syndrome: the effect of changing posture on shoulder range of movement. J Orthop Sports Phys Ther 2005;35:72-87.

35. Turner A, Baker E, Miller S. Increasing the impact force of the rear hand punch. Strength Cond J 2011;33:2-9.

36. Park SY, Kim H. Influence of isokinetic shoulder rotation strength by altered shoulder posture and characteristics of shoulder joint in overhead throwers. Korean Soc Living Environ Syst 2012;19: $817-24$.

37. Kim SY. A comparative study on isokinetic muscular strength of internal and external rotation on shoulder for shoulder injuries in tennis players. Korean J Sports Sci 2017;26:1359-66.

38. Byoun KS. Study of isokinetic muscular on the shoulder in Canadian canoe athlete [Master thesis]. Cheongju: Cheongju University; 2009

39. Vanderstukken F, Borms D, Berckmans K, Spanhove V, Cools AM. Relative scapular-muscle ratios during maximal isokinetic shouldergirdle strength performance in elite field hockey players. J Athl Train 2020;55:274-81. 